\title{
Translating GWAS Findings Into Therapies For Depression And Anxiety Disorders: Drug Repositioning Using Gene-Set Analyses Reveals Enrichment Of Psychiatric Drug Classes
}

\author{
Hon-Cheong $\mathrm{SO}^{* 1,2}$, Alexandria $\mathrm{LAU}^{1}$, Carlos Kwan-Long CHAU ${ }^{1}$, Sze-Yung WONG ${ }^{3}$ \\ ${ }^{1}$ School of Biomedical Sciences, The Chinese University of Hong Kong, Shatin, Hong Kong \\ ${ }^{2}$ KIZ-CUHK Joint Laboratory of Bioresources and Molecular Research of Common Diseases, Kunming \\ Zoology Institute of Zoology and The Chinese University of Hong Kong \\ ${ }^{3}$ Faculty of Medicine, The Chinese University of Hong Kong, Shatin, Hong Kong
}

Corresponding author: Hon-Cheong SO. Email: hcso@cuhk.edu.hk

\begin{abstract}
Depression and anxiety disorders are the first and sixth leading cause of disability worldwide according to latest reports from the World Health Organization. Despite their high prevalence and the significant disability resulted, there are limited advances in new drug development. On the other hand, the advent of genome-wide association studies (GWAS) has greatly improved our understanding of the genetic basis underlying psychiatric disorders.

In this work we employed gene-set analyses of GWAS summary statistics for drug repositioning. We explored five related GWAS datasets, including two on major depressive disorder (MDD-PGC and MDD-CONVERGE, with the latter focusing on severe melancholic depression), one on anxiety disorders, and two on depressive symptoms and neuroticism in the population. We extracted gene-sets associated with each drug from DSigDB and examined their association with each GWAS phenotype. We also performed repositioning analyses on meta-analyzed GWAS data, integrating evidence from all related phenotypes.

Importantly, we showed that the repositioning hits are generally enriched for known psychiatric medications or those considered in clinical trials, except for MDD-PGC. Enrichment was seen for antidepressants and anxiolytics but also for antipsychotics. We also revealed new candidates or drug classes for repositioning, some of which were supported by experimental or clinical studies. For example, the top repositioning hit using meta-analyzed p-values was fendiline, which was shown to produce antidepressant-like effects in mouse models by inhibition of acid sphingomyelinase and reducing ceramide levels. Taken together, our findings suggest that human genomic data such as GWAS are useful in guiding drug discoveries for depression and anxiety disorders.
\end{abstract}




\section{Introduction}

Depression and anxiety disorders are among the most common psychiatric disorders. According to the latest report by the World Health organization, depression affects more than 300 million people worldwide and is the leading cause of disability ${ }^{1}$. Anxiety disorders affects more than 260 million people and is the sixth leading cause of disability ${ }^{1}$. The two disorders are highly comorbid and might share common pathophysiologies ${ }^{2,3}$. Nevertheless, pharmacological treatment for major depressive disorder (MDD) or anxiety disorders (AD) has not seen much advance in the last two decades or so, with a lack of therapies having novel mechanisms of action. In addition, only about one third of MDD patients achieve complete remission after a single antidepressant trial ${ }^{4}$ and around 10 to $30 \%$ of patients are treatment-resistant ${ }^{5}$.

On the other hand, with the advent of high-throughput technologies such as genome-wide association studies (GWAS) in the last decade, we have gained a much better understanding of the genetic bases of many complex diseases. It is hoped that human genomics data will accelerate drug development for psychiatric disorders, especially due to the difficulties for animal models to fully mimic human psychiatric conditions such as depression ${ }^{6}$.

We hypothesize that gene-sets associated with antidepressants or anxiolytics, or more generally with psychiatric medications, will be enriched among the GWAS results of depression and anxiety phenotypes. If the gene-set analysis (GSA) approach is able to "re-discover" known treatments, it might also be able to reveal new therapies for depression and anxiety disorders. Practically, if the pathway targeted by a particular drug (or chemical) is significantly enriched in GWAS but the drug is not a known treatment for the disease, it may serve as a good candidate for repositioning.

With regards to GWAS-based drug discovery, the current focus is mainly on identification of new drug targets from the top GWAS hits. In an earlier study, Sanseau et al. ${ }^{7}$ identified the most significant GWAS hits from a range of diseases and compared them against known drug targets to find "mismatches" (i.e. drug indication different from the studied disorder) as candidates for repurposing. While it is intuitive and legitimate to focus on the most significant SNPs, for many complex traits the genetic architecture may be highly polygenic and variants of weaker effects may be "hidden". Moreover, given the complex and multifactorial etiologies of many complex diseases, the development of multi-target drugs with wide-ranging biological activities (known as "polypharmacology") is gaining increased attention (please refer to e.g. Anighoro et al. ${ }^{8}$ for a review). It is argued that multi-target drugs may have improved efficacy over highly selective pharmacological agents, as they tackle multiple pathogenic pathways in 
the system. A gene-set or pathway based approach to drug repositioning follows this multi-target paradigm.

Gene-set analysis is an established approach to gain biological insight into expression microarrays, GWAS or other high-throughput "omics" studies ${ }^{9,10}$. De Jong et al. made use of GSA to identify repurposing opportunities for schizophrenia ${ }^{11}$ and several top results were supported by the literature. In another very recent study, Gasper et al. ${ }^{12}$ performed further analyses of GSA results, and reported that GWAS signals of schizophrenia are enriched for neuropsychiatric medications as sample size increases. Another related study on schizophrenia was conducted by Ruderfer et al. ${ }^{13}$, who collected genome-wide significant GWAS variants and exome sequencing results and compared the identified genes against known or predicted drug targets. Significant enrichment was observed for antipsychotics.

In this study we take a different focus on depression and anxiety disorders, which are highly prevalent and disabling disorders. Besides considering individual GWAS studies of phenotypes related to depression and anxiety, we also performed analyses on combined GWAS summary statistics to improve the power.

\section{Methods}

\section{Overview of analytic approach}

Our analyses can be broadly divided into two steps. Firstly, we extracted gene-sets associated with a variety of drugs (or chemicals), and tested whether the gene-set associated with each individual drug is enriched among the GWAS results. The drugs ranked among the top (i.e. those with lower $p$-values) were considered potential candidates for repositioning. In the second step, we performed analyses on the drugs. We evaluated the prioritized drugs and tested which drug classes were enriched. As we have hypothesized above, we would specifically test whether antidepressants/anxiolytics and other psychiatric medications were enriched among the repositioning results.

\section{Genome-wide association studies data}

We considered five GWAS datasets that are associated with depression and anxiety. Two are studies of major depressive disorder (MDD), namely MDD-PGC ${ }^{14}$ and MDD-CONVERGE ${ }^{15}$. However, the two studies are different in a number of ways. The MDD-PGC sample $(N=$ $18,759)$ is composed of Caucasians of both sexes, while MDD-CONVERGE $(N=10,640)$ is a cohort of Chinese women. The MDD-CONVERGE sample mainly consists of hospital-ascertained cases affected by severe depression, of whom $\sim 85 \%$ had melancholic symptoms ${ }^{15}$. The MDD-PGC sample on the other hand is more heterogeneous and not specifically enriched for any subtypes of depression ${ }^{14}$. 
Another two GWAS studies were meta-analyses on depressive symptoms and neuroticism conducted by the Social Science Genetics Association Consortium (SSGAC) ${ }^{16}$. The meta-analysis on depressive symptoms (SSGAC-DS) included the MDD-PGC study ( $N=$ 18,759) and a case-control sample from the Genetic Epidemiology Research on Aging (GERA) Cohort $(N=56,368)$, but it also comprised an UK BioBank sample made up of general population $(N=105,739)$. Depressive symptoms were measured by a self-reported questionnaire. We also included another study on neuroticism (SSGAC-NEU) $(N=170,906)$, as this personality trait is known to be closely associated with depression and anxiety disorders 17. In addition, antidepressants may affect personality traits, including a reduction in neuroticism, independent of their effects on depressive symptoms ${ }^{18}$.

The fifth dataset is a GWAS meta-analysis of anxiety disorders, including generalized anxiety disorder, panic disorder, social phobia, agoraphobia, and specific phobias ${ }^{19}$. We extracted the GWAS results of the case-control analyses $(N=17,310)$.

GWAS summary results were downloaded from https://www.med.unc.edu/pgc/results-and-downloads and https://www.thessgac.org/data.

\section{Extracting gene-sets associated with each drug}

We made use of the DSigDB database ${ }^{20}$ to extract gene-sets related to each drug. DSigDB holds gene-sets for a total of 17839 unique compounds. The gene-sets were compiled according to multiple sources: (1) bioassay results from PubChem ${ }^{21}$ and $\mathrm{ChEMBL}^{22}$; (2) kinase profiling assay from the literature and two kinase databases (Medical Research Council Kinase Inhibitor database and Harvard Medical School Library of Integrated Network-based Cellular Signatures database); (3) differentially expressed genes after drug treatment (with $>2$ fold-change compared to controls), as derived from the Connectivity Map ${ }^{23}$; and (4) manually curated and text mined drug targets from the Therapeutics Targets Database (Qin et al., 2014) and the Comparative Toxicogenomics Database ${ }^{24}$. We downloaded the entire database from http://tanlab.ucdenver.edu/DSigDB. The above sources captured different aspects of drug properties, for example differentially expressed genes from perturbation experiments might be different from drug target genes defined in bioassay studies. Besides performing analyses based on the whole database which incorporates a broad definition of drug-related genes, we also performed a separate enrichment analysis for genes derived from PubChem and ChEMBL only, as they represent conventionally defined "drug targets" that are more well-studied and perhaps more directly associated with drug actions.

It should be noted that although the focus is on drug "repositioning", the analytic framework is general and can apply to any drugs with some known associated genes. Indeed 
DSigDB contains a substantial number of drugs which do not have an approved indication yet, which were still included in our analyses.

\section{Gene-set analysis (GSA) approach}

We first converted the SNP-based test results to gene-based test results. We employed fastBAT ${ }^{25}$ (included in the software package GCTA) for gene-based analyses. FastBAT computes the sum of chi-square statistics over all SNPs within a gene and uses an analytic approach to compute the $p$-value. Gene size and linkage disequilibrium patterns are taken into account when computing the $p$-values. The same statistical approach for gene-based tests is also used by two other popular programs, VEGAS ${ }^{26}$ and PLINK ${ }^{27}$, although they computed $p$-values by simulations or permutations. FastBAT has been shown to be equivalent to VEGAS and PLINK at higher $p$-values ( $>1 \mathrm{E}-06)$ and more accurate than these two programs for smaller $p^{25}$. We ran fastBAT with the default settings and used the 1000 Genome genotype data as the reference panel.

We then performed a standard GSA by comparing gene-based test statistics within and outside the gene-set. We adopted the same approach as implemented in MAGMA ${ }^{28}$, which is also reviewed in de Leeuw et al. ${ }^{10}$. Briefly, gene-based $p$-values are first converted to z-statistics by $z=\Phi^{-1}(p)$, where $\Phi^{-1}$ is the probit function (more negative z-values represent stronger statistical associations). We then employed a single-sided two-sample $t$-test to see if the mean $z$-statistics of genes within the gene-set is lower than that outside the gene-set. To avoid results driven by only a few genes, we only considered drugs with at least 5 genes in their gene-sets. A total of 5232 drugs were included for final analyses.

\section{Combining p-values across datasets}

Besides analyzing each GWAS dataset in turn for repositioning opportunities, we also considered the aggregate contribution of all datasets, as depression, anxiety and neuroticism are closely connected to each other. The combined analysis is complementary to the study of individual phenotypes. A combined analysis improves study power by increasing total sample size; on the other hand, study of individual phenotypes may reveal drugs or drug classes that are specifically useful for particular disease symptoms or subtypes, for example melancholic depression.

We performed meta-analysis of $p$-values based on two methods, the Simes' method ${ }^{29}$ and the Brown's approach ${ }^{30,31}$. The Simes' method is valid under positive regression dependencies ${ }^{32}$. Brown's method is similar to Fisher's method but also accounts for dependencies in $p$-values.

Briefly, assuming $k$ p-values, Fisher showed that the statistic $T=\sum-2 \log P_{i}$ should follow 
a chi-squared distribution with $2 k$ degrees of freedom if the $p$-values are independent. Brown's method is an extension of Fisher's approach by estimating the statistic $T$ with a re-scaled chi-square distribution $T \sim c \chi_{2 f}^{2}$ where

$$
f=\frac{E(T)^{2}}{\operatorname{var}(T)} \text { and } c=k / f
$$

The expectation of the statistic $T$ can be estimated by $E(T)=2 k$ and the variance by $\operatorname{var}(T)=4 k+2 \sum_{i<j} \operatorname{cov}\left(-2 \log P_{i},-2 \log P_{j}\right)$. We estimated the covariance empirically from the observed $p$-value vectors of different phenotypes.

The MDD-CONVERGE sample includes only Chinese subjects and does not overlap with other datasets, but we accounted for overlapping samples (with Brown's or Simes' method) in the remaining GWAS studies. We did not include MDD-PGC when combining $p$-values as this sample is already included in the GWAS meta-analysis of depressive symptoms ${ }^{16}$.

\section{Testing for enrichment of psychiatric and other drug classes}

We considered three sources when defining psychiatric drug-sets in our analyses. The first set came from drugs listed in the Anatomical Therapeutic Classification (ATC) system downloaded from KEGG. We extracted three groups of drugs: (1) all psychiatric drugs (coded "N05" or "N06"); (2) antipsychotics (coded "N05A"); (3) antidepressants and anxiolytics (coded "N05B" or "N06A"). The second source was from MEDication Indication resource (MEDI) ${ }^{33}$ derived from four public medication resources, namely RxNorm, Side Effect Resource 2 (SIDER2), Wikipedia and MedlinePlus. A random subset of the extracted indications was checked by physicians. The MEDI high-precision subset (MEDI-HPS), with an estimated curation precision of $92 \%$, was used in our analyses ${ }^{33}$. Since only known drug indications are included in ATC or MEDI-HPS, we also included an expanded set of drugs that are considered for clinical trials (as listed on https://clinicaltrials.gov). These drugs are usually promising candidates supported by preclinical or clinical studies. A precompiled list of these drugs was obtained from https://doi.org/10.15363/thinklab.d212. We also examined enrichment for closely related disorders in combinations, including schizophrenia with bipolar disorder (BD), as well depression with anxiety.

The above represents a hypothesis-driven analysis of psychiatric drug classes. To explore whether other drug groups may be repositioned for disease treatment, we also performed a comprehensive enrichment analysis of all ATC level 3 drug classes. To avoid the results being driven by too few drugs in a class, we limited the analyses to drug classes with at least 5 members. Note that in the previous step we have found individual drugs as repositioning candidates, but we also hope to find out which drug classes may be promising for repositioning, 
which can also provide insights into potentially new mechanisms of actions in future development.

We performed enrichment tests of repositioning hits for known drug classes, in a manner similar to the GSA described above. P-values are first converted to $z$-statistics, and the mean z-score within each drug class is compared against the theoretical null of zero (self-contained test) and against other drugs outside the designated drug class (competitive test) with one-sided tests.

It is reasonable to believe that the current antidepressants or anxiolytics are not the only drugs that have therapeutic effects; in other words, a certain proportion of drugs in the "competing set" might also have therapeutic potential against depression or anxiety. Therefore, results of the competitive tests should be interpreted with this potential limitation in mind. In this paper we presented the drug-set enrichment results of both self-contained and competitive tests.

\section{Literature search and curation of results}

We extracted the top 20 repositioning hits of each psychiatric trait and meta-analyzed results, with drug-related gene-sets derived from either the entire database or drug targets defined by PubChem or ChEMBL. We performed a systematic search in PubMed and Google scholar using the following terms: Drug_name AND (depression OR depressive OR antidepressant OR anxiety OR panic OR phobia OR anxiolytic). References therein were looked up as necessary. The search was performed in June to August 2017.

\section{Correction for multiple testing}

We employed the false discovery rate (FDR) approach (which controls the expected proportion of false positives among those declared to be significant) to account for multiple testing ${ }^{34}$. FDR-adjusted $p$-values (or $q$-values) were computed by the $\mathrm{R}$ function p.adjust with the Benjamini-Hochberg $(\mathrm{BH})$ procedure ${ }^{34}$. The primary $q$-value threshold was set at 0.05 , while results with $q<0.1$ were regarded as suggestive associations.

\section{RESULTS}

\section{Enrichment of psychiatric drug classes among the drugs repositioned from gene-set analyses}

Table 1-3 and Supplementary Tables 1-3 show the enrichment $p$-values and $q$-values for major psychiatric drug classes amongst the drugs repositioned from GSA. We observed that the drugs repositioned from most GWAS of anxiety and depressive traits are generally enriched for known psychiatric medications. 
First we consider the three datasets (MDD-CONVERGE, MDD-PGC, SSGAC-DS) which focus on depression traits (Table 1 and Supplementary Table 1). On the whole the MDD-CONVERGE sample showed the strongest enrichment with the greatest number of significant results. Significant enrichment was seen for antipsychotics and antidepressants or anxiolytics within ATC and MEDI-HPS categories. In contrast, we did not observe any significant enrichment for drugs repositioned from the MDD-PGC sample. The SSGAC-DS study included MDD-PGC data but the latter only comprised $\sim 10 \%$ of the total sample size. For SSGAC-DS, we observed enrichment of drugs for schizophrenia and BD, and suggestive associations with medications for anxiety and depression listed in clinicalTrial.gov.

As for GWAS studies on neuroticism (SSGAC-NEU) and anxiety disorders, there was evidence of enrichment for most psychiatric drug classes under study. Interestingly, for neuroticism, the strongest enrichment was for antipsychotics (lowest $q=2.28 \mathrm{E}-09$ ) instead of antidepressants. Table 2 and Supplementary Table 2 show the enrichment $p$-values and $q$-values respectively.

For analyses involving meta-analyzed GWAS data across all datasets (Table 3 and Supplementary Table 3), enrichment was observed for all psychiatric drug classes, with generally stronger or at least comparable statistical associations when compared to enrichment tests of individual GWAS. The results of Brown's and Simes' tests were largely consistent with each other.

We also performed an analysis based on drug target genes derived from PubChem or ChEBML only. The results (including corresponding q-values) were given in Supplementary Table 4 and were largely similar to the above findings.

Table 4 and Supplementary Table 5 shows the results of enrichment tests across all ATC level 3 drug classes based on gene-sets derived from the whole DSigDB database. Table 5 and Supplementary Table 6 shows the findings from the same analysis but with gene-sets derived from PubChem or ChEBML only. We consider results from both of the analyses here. For MDD-PGC, anti-infective and anti-inflammatory agents were significantly enriched. Interestingly, hypnotics/sedatives and anxiolytics, which were commonly used as short-term therapies especially at the acute phase of illness $^{35}$, are also ranked among the top. Antidepressants or other psychiatric drugs however were not enriched. For MDD-CONVERGE, drug classes pertaining to corticosteroids were ranked highly. Notably, antidepressants and antipsychotics were ranked within the top 5 in our two sets of analyses. For anxiety disorders, antipsychotics and antidepressants were the two most strongly enriched medication classes. 
Beta-blocking agents were ranked among the top for anxiety disorders. Beta adrenergic blockers, especially propranolol, have been clinically used in anxiety disorders for a long time, although the efficacy still remains uncertain ${ }^{36}$. As for depressive symptoms, dopaminergic and antiepileptic agents were listed among the top, and interestingly lipid-lowering agent was also on the top list. As for neuroticism, antipsychotics was the most strongly enriched drug class, and antidepressants was also ranked within the top 10. Other drug classes listed in top 10 also included hypnotics/sedatives, anxiolytics and dopaminergic agents. The full results are shown in Supplementary Tables 5 to 6 .

\section{Top repositioning hits}

\section{Based on gene-sets derived from the whole DSigDB database}

We found several interesting repositioning hits that were supported by previous studies (Table 6; Supplementary Table 7 gives a fully annotated list of the top 20 drugs). The top-ranked repositioning hit identified in the meta-analysis was fendiline (Brown's $p=1.06 \mathrm{E}-11, q=$ $5.55 \mathrm{E}-8$ ), a non-selective calcium channel blocker. Fendiline was shown to exert antidepressant-like effects in a mouse model by inhibition of acid sphingomyelinase (ASM) activity and reduction of ceramide concentrations in the hippocampus ${ }^{37}$. A drop in ceramide concentrations might lead to increased neurogenesis and improved neuronal maturation and survival ${ }^{37}$. The drug was ranked among the top for MDD-PGC, SSGAC-DS and neuroticism.

As for individual phenotypes, some interesting candidates for MDD-CONVERGE include DHEA, a neurosteroid with evidence of antidepressive effects in a double-blind RCT; naringenin chalcone, a citrus bioflavonoid shown to be effective in mouse models ${ }^{38}$; amoxapine, a tetracyclic antidepressant ${ }^{39}$.

Candidates for MDD-PGC include ibuprofen, an NSAID shown to be associated with lower depressive symptoms in osteoarthritis patients; piperlongumine, a constituent of the fruit of Piper longum, which was shown to confer resistance against stress in a mouse model ${ }^{40}$; and sanguinarine, a selective mitogen-activated protein kinase phosphatase-1 (Mkp-1) inhibitor which produced antidepressant-like effect in rats ${ }^{41}$.

For anxiety disorders, candidates included a known antidepressant trazodone and a serotonin agonist quipazine that may increase brain serotonin levels ${ }^{42}$. For depressive symptoms, alsterpaullone, a glycogen synthase kinase-3 $\beta$ (GSK-3 $\beta$ ) inhibitor ${ }^{43}$. Increased activation of GSK-3 $\beta$ was also associated with depression-like behavior in mouse models, which could be alleviated by GSK-3 $\beta$ inhibitors ${ }^{44}$. In addition, inhibition of GSK3 has been postulated as a major mechanism of action by the mood stabilizer lithium ${ }^{45}$. A NMDA receptor antagonist H-7 was also top-listed ${ }^{46}$. 
Among the top repositioning hits from the individual and meta-analysis results, a number of them are calcium channel blockers (CCB). These include fendiline, perhexiline, prenylamine and felodipine (prenylamine was withdrawn from the market due to risk of QT prolongation and torsades de pointes ${ }^{47}$ ). Although with the exception of fendiline, no direct experimental or clinical studies have shown antidepressant or anxiolytic properties of the above drugs, CCB as a whole have been proposed as treatment for various psychiatric disorders. CCB has been mostly studied for the treatment of mania, recently reviewed in Cipriani et al. ${ }^{48}$. However the number of quality double-blind randomized controlled trials (RCT) was small, and there is yet no sufficient evidence to suggest the use of CCB in treating manic symptoms. As for depression, a recent pilot (patient-only) study of isradipine on bipolar depression showed positive results ${ }^{49}$. Another CCB, nicardipine, was reported to enhance the antidepressant action of electroconvulsive therapy ${ }^{50}$. Notwithstanding the mixed evidence, CCB are probably still worthy of further investigation for depression and anxiety disorders, given the biological relevance of calcium signaling, preliminary support from clinical studies and the wide availability as well as known safety profiles of this drug class.

\section{Based on Gene-sets derived from PubChem and ChEMBL}

A manually annotated list of the top 20 prioritized drugs is given in supplementary Table 8 . Some highlighted candidates are also shown in Table 6. Some repositioning hits for MDD-CONVERGE included oxotremorine-M, a muscarinic acetylcholine receptor agonist that may ameliorate depressive symptoms and restore hippocampal neurogenesis in an animal model $^{51}$ and capeserod, a 5-HT4 receptor agonist shown effective in a mouse model ${ }^{52}$. For MDD-PGC, top-listed drugs include three NSAIDs, namely ibuprofen, meclofenamate and flufenamic acid, which possess anti-inflammatory actions that may also be beneficial for depression $^{53,54}$. Remarkably, our analysis recovered a known augmentation therapy for

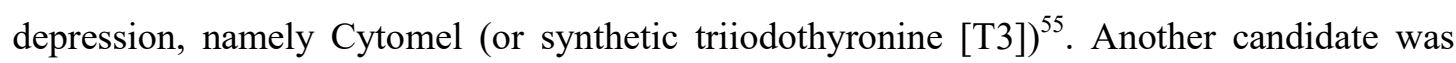
guanidinonaltrindole di-trifluoroacetate, a $\kappa$-opioid receptor inhibitor with antidepressant-like and anxiolytic-like efficacy in rat models ${ }^{56}$.

There were a number of noteworthy candidates from the analysis results of anxiety disorders. Notably, the top-ranked drugs contain pregabalin and gabapentin, two drugs with similar mechanisms which have been shown anxiolytic effects in clinical trials (especially pregabalin) ${ }^{57,58}$; clomipramine, a known tricyclic antidepressant; and trazodone, another known antidepressant belonging to the serotonin antagonist and reuptake inhibitor class. Some other noteworthy candidates include ritanserin, a selective 5- $\mathrm{HT}_{2 \mathrm{~A}}$ and $5-\mathrm{HT}_{2 \mathrm{C}}$ receptor antagonist ${ }^{59-61}$; pindolol, a beta blocker with partial beta-adrenergic receptor agonist activity 
and a possible augmentation therapy for depression ${ }^{62,63}$; atomoxetine, a norepinephrine reuptake inhibitor.

For depressive symptoms, the top-listed candidates include prochlorperazine and raclopride, which are antipsychotics; protriptyline, a tricyclic antidepressant; oleamide, a cannabinoid receptor type 1 (CB1) receptor agonist of potential antidepressant effects in animal models ${ }^{64,65}$; ellagic acid and chebulinic acid (an ellagitannin), natural phenol antioxidants with some evidence of improving depressive traits again in animal models ${ }^{66-68}$. Also of note is the nicotinic agonist DMPP, as nicotine has been shown to have antidepressant properties in pre-clinical and clinical studies ${ }^{69}$; the antidepressant effects may be due to initial activation of the nicotinic receptor followed by densensitization leading to long term antagonism ${ }^{69}$. For neuroticism, again quite a number of top hits are $\mathrm{CCB}$, and the $\mathrm{CCB}$ fendiline was the top-ranked candidate. The repositioning hits derived from meta-analyzed $p$-values were covered above.

\section{DISCUSSION}

In this study we leveraged large-scale GWAS summary data and analyzed gene-sets associated with drugs to uncover repositioning opportunities for depression and anxiety disorders. It is encouraging that we observed significant enrichment for known psychiatric medications or drugs considered in clinical trials. Remarkably, antipsychotics and antidepressants were the two most significantly enriched drug classes in our combined analysis (with gene-sets derived from the whole DSigDB). Our findings provide support for the validity of GSA in drug repurposing. In addition, we reveal a number of interesting candidates for repurposing that are supported by prior studies. Although relatively few susceptibility variants of genome-wide significance have been found for depression and anxiety disorders, our findings suggest that leveraging variants with weaker associations, for example by GSA, might still contribute valuable information to the discovery of novel therapies.

While we have included three datasets (SSGAC-DS, MDD-PGC, MDD-CONVERGE) directly related to depression, the enrichment results are quite different. Both MDD-PGC and MDD-CONVERGE are case-control GWAS studies on MDD; however, the drugs and drug classes enriched were quite different. The enrichment for psychiatric drug classes were generally weaker for MDD-PGC. The discrepancy might be due to the differences between the two samples. As described above, the two samples differ by gender, ethnicity and the severity of depression. In addition, due to the lower awareness and possibly stronger resistance to seeking medication attention for depression in China, the disease severity in the CONVERGE cohort may be even higher than expected. It is widely accepted that MDD is a heterogeneous disorder, with a variety of clinical presentations and possibly divergent pathophysiologies ${ }^{70}$. 
By recruiting a more homogeneous group of patients, the CONVERGE study might have better power in detecting susceptibility genes despite a lower sample size. Indeed, MDD-CONVERGE revealed two genome-wide significant loci while none was found in the MDD-PGC study. It is also worth mentioning that previous meta-analyses showed that the response to antidepressant depends on the baseline severity of depression ${ }^{71,72}$. The studies reported that effects of antidepressants were largest for the most severely depressed group, but smaller for mild to moderate depression. Our findings, although based on a different study paradigm, are broadly in line with this clinical observation.

It is noteworthy that the repositioning hits are not only enriched for antidepressants or anxiolytics but also antipsychotics. A meta-analysis by Spielmans et al. revealed that atypical antipsychotics are effective as adjunctive treatment for treatment-resistant depression ${ }^{73}$. Zhou et al. also reached a similar conclusion in a recent network meta-analysis ${ }^{74}$. Atypical antipsychotics may also be useful for anxiety disorders and symptoms ${ }^{75-77}$, although further studies are required and that the benefits need to be balanced against the side-effects. Furthermore, a shared genetic basis between schizophrenia and depression is well-established 78 , and a recent study also found significant genetic correlation between neuroticism and schizophrenia ${ }^{79}$. Epidemiology studies also demonstrated associations of neuroticism with schizophrenia $^{80}$.

Several other top-ranked drug classes are also worth mentioning. For MDD-PGC, although antidepressant was not significantly enriched, anti-inflammatory agents was listed among the top. Numerous studies have suggested a role of inflammation in depression, which were reviewed elsewhere ${ }^{81}$. For example, blood levels of inflammatory biomarkers (e.g. IL-1beta, IL-6, TNF, C-reactive protein) were elevated in patients with depression ${ }^{81}$. A large-scale observational study suggested that non-steroidal inflammatory drugs (NSAID), particularly low-dose acetylsalicylic acid, may reduce risk of depression ${ }^{82}$. A meta-analysis of RCTs also reported beneficial effects of anti-inflammatory treatment including both NSAID and cytokine inhibitors ${ }^{83}$.

Another interesting finding is that drug classes related to corticosteroids were highly ranked for MDD-CONVERGE, which is composed of mainly severe melancholic depressive patients. A number of studies ${ }^{84-86}$ have shown that hyperactivity of the hypothalamic-pituitary axis is an important feature of melancholic depression. As with other kinds of gene-set analyses, the current approach of GSA does not delineate the exact direction of drug effects. It may be concluded that corticosteroids or drugs targeting relevant pathways might be of clinical significance to melancholic depression; however, whether corticosteroids themselves or drugs blocking their actions would be useful remains to be investigated. Glucocorticoid 
synthesis inhibitors and receptor antagonists have been shown to exhibit antidepressant effects $^{87,88}$. Conversely, several short-term trials or studies reported antidepressant properties of corticosteroids themselves; one possible mechanism is the restoration of negative feedback of the HPA axis at the hypothalamic and pituitary levels ${ }^{89-92}$. In any case, our findings provide a proof-of-concept example that making use of appropriate GWAS (or other human genomic) data might help to develop more targeted treatment for disease subtypes.

A few other drug classes may also be worthy of attention. Dopaminergic agents were ranked among the top for depressive symptoms; stimulants including dopaminergic agents have been tested in clinical trials for unipolar and bipolar depression ${ }^{93-96}$. We also observed that anti-migraine medications were highly ranked in the list. An increased rate of depression among migraine patients is well-established ${ }^{97}$, and antidepressants (mainly tricyclics) have been used for migraine prophylaxis ${ }^{98}$. The effects of anti-migraine medications on depressive symptoms however remains to be elucidated. Lipid-lowering agents was top-listed for depressive symptoms (based on all gens in DSigDB) and anxiety disorders (based on drug target genes from PubChem and ChEMBL), and studies have shown potential benefits of statins in depression ${ }^{99}$, and when used with concomitant SSRI ${ }^{100}$. However, some studies have also reported increased depressive symptoms with statins ${ }^{101}$, hence the exact relationship may be complex and may differ by patient characteristics. Whether other types of lipid-lowering drugs may be beneficial is another topic worthy of further investigations.

In this study we employed the GSA approach to drug repositioning. The current study is complementary to our recent repositioning attempt using a new framework in which the drug-induced transcriptome is compared against GWAS-imputed expression profiles ${ }^{102}$. Each of these two methods has their own advantages and disadvantages. The methodology of finding reversed expression patterns (as detailed in So et al. ${ }^{102}$ ) has a unique advantage of accounting for the directions of associations. It also takes into account the functional impact of variants on expression and is intuitive from a biological point of view. While differentially expressed genes can be included in gene-sets, the actual (quantitative) expression changes are not considered which results in a loss of information. GSA also does not delineate the directions of effects. Nevertheless, GSA can directly make use of knowledge concerning known drug targets and other information on drug-related genes, for which more databases are available. Moreover, in the 'reversed transcriptome' approach ${ }^{102}$, one only considers functional effects of the SNPs on expression, but genetic variants may also contribute to disease pathogenesis via other mechanisms, such as splicing or changes in protein function. The gene-based test in the current analysis is based on combining statistical evidence of individual SNPs in a general manner, and may capture a wider range of effects on disease risk. Also, the transcriptome comparison approach involves "imputing" expression levels; since the major reference transcriptome 
dataset (GTEx) is mainly composed of Caucasians (84.6\%) with greater proportion of males (65.6\%) (https://www.gtexportal.org/home/tissueSummaryPage, accessed $7^{\text {th }}$ Sep 2017), the quality of imputation for other ethnicities and females might be less reliable, for example when applied to the MDD-CONVERGE dataset.

Just as medications acting on different pathways might have synergistic therapeutic effects, we believe that it is beneficial to have different approaches for computational drug repositioning to complement each other. Of course, computational methods leveraging human genomic data are not the only means to drug discovery. We believe that a combination of a variety of approaches, including experimental and computational ones, is required to speed up drug repurposing and discoveries.

Our enrichment analyses support the application of GSA in drug repositioning in depression and anxiety. However, we stress that our repositioning results should be validated in further pre-clinical and clinical studies before translation to practice. GSA analyses do not provide information on the direction of effects, as discussed previously. Measures of statistical significance also do not provide definitive evidence for the actual therapeutic effects of the repositioned drugs.

In summary, we have performed a drug repositioning analyses on depression and anxiety disorders, using a gene-set analysis approach considering five related GWAS studies. We showed that the repositioned drugs are in general enriched for known psychiatric medications or those considered in clinical trials. Remarkably, antipsychotics and antidepressants were ranked among the top even if we considered all level 3 ATC drug classes. The results lend further support to the usefulness of human genomic data in guiding drug development in psychiatry, and we hope that the rapid advances in psychiatric genomics research will translate into benefits for patients in the foreseeable future.

\section{Acknowledgements}

This work is partially supported by the Lo-Kwee Seong Biomedical Research Fund and a Direct Grant from the Chinese University of Hong Kong. We also thank Professor Stephen K.W. Tsui and the Hong Kong Bioinformatics Centre for computing support. We would also like to acknowledge the Psychiatric Genomics Consortium, the CONVERGE Consortium, the Social Science Genetics Association Consortium and Otawa et al. for providing open access to full GWAS summary results. 


\section{Author contributions}

H.-C.S. conceived and designed the study. H.-C.S. performed data analyses with assistance from C.K.L.C. H.-C.S. interpreted the data. A.L. and S-Y.W. performed drug annotations. H.-C.S. wrote the manuscript and supervised the study. 
Table 1 Enrichment $p$-values of repositioning hits derived from GWAS of major depressive disorder (MDD) and depressive symptoms

\begin{tabular}{|c|c|c|c|c|c|c|}
\hline Disorder & $\begin{array}{c}\text { MDD-CON } \\
\text { Self }\end{array}$ & $\begin{array}{c}\text { MDD-CON } \\
\text { Compet }\end{array}$ & $\begin{array}{c}\text { MDD-PGC } \\
\text { Self }\end{array}$ & $\begin{array}{c}\text { MDD-PGC } \\
\text { Compet }\end{array}$ & $\begin{array}{c}\text { DepSym } \\
\text { Self }\end{array}$ & $\begin{array}{l}\text { DepSym } \\
\text { Compet }\end{array}$ \\
\hline \multicolumn{7}{|l|}{ ATC classification } \\
\hline Antipsychotics & 2.50E-04 & 1.13E-02 & $1.00 \mathrm{E}+00$ & $9.98 \mathrm{E}-01$ & 1.35E-03 & $4.48 E-02$ \\
\hline Antidepressants or anxiolytics & 2.10E-06 & $7.64 \mathrm{E}-04$ & $1.00 \mathrm{E}+00$ & $9.82 \mathrm{E}-01$ & 1.90E-02 & 3.44E-01 \\
\hline All ATC psychiatric drugs & 3.54E-08 & $1.83 E-03$ & $1.00 \mathrm{E}+00$ & $9.98 \mathrm{E}-01$ & 5.17E-07 & $9.62 \mathrm{E}-03$ \\
\hline \multicolumn{7}{|l|}{$M E D I-H P S$} \\
\hline Schizophrenia and Bipolar & 3.06E-07 & 2.04E-04 & $1.00 \mathrm{E}+00$ & $1.00 \mathrm{E}+00$ & 2.90E-02 & $4.68 \mathrm{E}-01$ \\
\hline Anxiety and Depression & 2.98E-07 & $6.59 E-04$ & $1.00 \mathrm{E}+00$ & $9.99 \mathrm{E}-01$ & 2.08E-03 & $2.02 \mathrm{E}-01$ \\
\hline All psychiatric drugs & $1.77 E-10$ & $4.40 \mathrm{E}-05$ & $1.00 \mathrm{E}+00$ & $1.00 \mathrm{E}+00$ & 1.35E-03 & $3.15 \mathrm{E}-01$ \\
\hline \multicolumn{7}{|l|}{ ClinicalTrial.gov } \\
\hline Anxiety disorders & 3.20E-07 & 2.18E-03 & $1.00 \mathrm{E}+00$ & $9.92 \mathrm{E}-01$ & 4.97E-04 & $1.16 \mathrm{E}-01$ \\
\hline Depression & 9.45E-07 & 2.27E-02 & $1.00 \mathrm{E}+00$ & $9.99 \mathrm{E}-01$ & $5.76 \mathrm{E}-05$ & $8.67 \mathrm{E}-02$ \\
\hline Bipolar disorder & $1.64 \mathrm{E}-03$ & $1.69 \mathrm{E}-01$ & $1.00 \mathrm{E}+00$ & $9.97 \mathrm{E}-01$ & $1.55 E-05$ & 9.33E-03 \\
\hline Schizophrenia & $5.42 E-05$ & $9.66 \mathrm{E}-02$ & $1.00 \mathrm{E}+00$ & $9.96 \mathrm{E}-01$ & 4.39E-05 & $9.42 \mathrm{E}-02$ \\
\hline Anxiety + Depression & 3.14E-09 & $1.69 \mathrm{E}-03$ & $1.00 \mathrm{E}+00$ & $1.00 \mathrm{E}+00$ & $1.23 E-05$ & $6.07 E-02$ \\
\hline Schizophrenia + Bipolar & $2.62 E-05$ & $9.12 \mathrm{E}-02$ & $1.00 \mathrm{E}+00$ & $9.96 \mathrm{E}-01$ & 4.85E-07 & $8.78 E-03$ \\
\hline All psychiatric drugs & $6.89 \mathrm{E}-11$ & $1.43 E-03$ & $1.00 \mathrm{E}+00$ & $1.00 \mathrm{E}+00$ & 5.09E-09 & $1.49 \mathrm{E}-02$ \\
\hline
\end{tabular}

Self: self-contained test; Compet, competitive test. Test results with $q$-value $<0.05$ are in bold. Results with $q$-value between 0.05 and 0.1 are in italics. Full tables of $q$-values are presented in Supplementary Table 1.

MDD-CON, MDD with GWAS data from the CONVERGE Consortium; MDD-PGC, MDD with GWAS data from the Psychiatric Genomics Consortium; DepSym, GWAS of depressive symptoms from the Social Science Genetics Association Consortium (SSGAC). All p-values are based on one-tailed tests. 
Table 2 Enrichment $p$-values of repositioning hits derived from GWAS of anxiety disorders and neuroticism

\begin{tabular}{|c|c|c|c|c|}
\hline Disorder & AnxietyCC Self & AnxietyCC Compet & Neurotic Self & Neurotic Compet \\
\hline \multicolumn{5}{|l|}{ ATC classification } \\
\hline Antipsychotics & $1.71 \mathrm{E}-03$ & 4.47E-04 & $1.21 \mathrm{E}-10$ & $1.52 \mathrm{E}-10$ \\
\hline Antidepressants or anxiolytics & $1.35 \mathrm{E}-02$ & 5.23E-03 & 1.09E-03 & $1.45 E-03$ \\
\hline All ATC psychiatric drugs & $6.67 E-03$ & 7.93E-04 & $4.88 \mathrm{E}-12$ & 7.99E-12 \\
\hline \multicolumn{5}{|l|}{$M E D I-H P S$} \\
\hline Schizophrenia and Bipolar & 7.51E-03 & 2.30E-03 & 1.29E-06 & 1.98E-06 \\
\hline Anxiety and Depression & 8.24E-03 & $2.46 \mathrm{E}-03$ & 5.98E-05 & $9.01 E-05$ \\
\hline All psychiatric drugs & 4.18E-04 & 3.82E-05 & 1.02E-07 & 1.77E-07 \\
\hline \multicolumn{5}{|l|}{ ClinicalTrial.gov } \\
\hline Anxiety disorders & 2.84E-02 & 7.94E-03 & 2.70E-03 & 3.82E-03 \\
\hline Depression & 1.17E-02 & $1.55 \mathrm{E}-03$ & 8.62E-02 & $1.14 \mathrm{E}-01$ \\
\hline Bipolar disorder & $1.56 \mathrm{E}-02$ & 3.53E-03 & 5.93E-03 & 7.94E-03 \\
\hline Schizophrenia & $3.49 \mathrm{E}-03$ & 3.43E-04 & 9.70E-04 & $1.47 \mathrm{E}-03$ \\
\hline Anxiety + Depression & 1.78E-02 & 2.33E-03 & $4.09 E-02$ & $5.70 E-02$ \\
\hline Schizophrenia + Bipolar & 3.12E-03 & 2.69E-04 & 5.32E-04 & 7.84E-04 \\
\hline All psychiatric drugs & $8.26 \mathrm{E}-03$ & 3.61E-04 & $2.16 \mathrm{E}-03$ & 3.34E-03 \\
\hline
\end{tabular}

Self: self-contained test; Compet, competitive test. Test results with $q$-value $<0.05$ are in bold. Results with $q$-value between 0.05 and 0.1 are in italics. Full tables of $q$-values are presented in Supplementary Table 2.

Anxiety CC, GWAS of anxiety disorders case-control sample; neurotic, GWAS of neuroticism in general population. 
Table 3 Enrichment $p$-values of repositioning hits derived from meta-analysis of GWAS $p$-values from MDD-CONVERGE, MDD-PGC, SSGAC-DS and SSGAC-NEU

\begin{tabular}{|c|c|c|c|c|}
\hline Disorder & Brown Self & Brown Compet & Simes Self & Simes Compet \\
\hline \multicolumn{5}{|l|}{ ATC classification } \\
\hline Antipsychotics & 2.31E-09 & 8.77E-07 & 4.64E-07 & 9.11E-06 \\
\hline Antidepressants or anxiolytics & 8.30E-10 & 3.19E-06 & 2.01E-07 & 9.57E-06 \\
\hline All ATC psychiatric drugs & 2.51E-18 & $3.16 \mathrm{E}-10$ & 8.38E-12 & 3.03E-08 \\
\hline \multicolumn{5}{|l|}{ MEDI-HPS } \\
\hline Schizophrenia and Bipolar & 5.19E-08 & 5.70E-05 & 7.14E-06 & 1.79E-04 \\
\hline Anxiety and Depression & $1.63 E-10$ & 3.18E-06 & $1.35 E-06$ & 8.95E-05 \\
\hline All psychiatric drugs & $2.36 \mathrm{E}-13$ & 2.85E-07 & $1.83 E-08$ & $6.63 E-06$ \\
\hline \multicolumn{5}{|l|}{ ClinicalTrial.gov } \\
\hline Anxiety disorders & 3.47E-08 & 4.63E-04 & 1.98E-04 & 7.49E-03 \\
\hline Depression & $4.33 \mathrm{E}-10$ & 3.82E-04 & 1.04E-06 & $6.14 \mathrm{E}-04$ \\
\hline Bipolar disorder & 5.53E-09 & 7.43E-05 & 8.07E-07 & 7.47E-05 \\
\hline Schizophrenia & $1.61 \mathrm{E}-10$ & 9.69E-05 & 2.04E-06 & 4.70E-04 \\
\hline Anxiety + Depression & 4.94E-12 & 4.19E-05 & 5.33E-08 & 7.93E-05 \\
\hline Schizophrenia + Bipolar & $2.56 \mathrm{E}-12$ & 6.00E-06 & 5.84E-08 & 3.07E-05 \\
\hline All psychiatric drugs & $1.23 \mathrm{E}-16$ & 9.29E-07 & 2.94E-10 & $4.86 \mathrm{E}-06$ \\
\hline
\end{tabular}

Self: self-contained test; Compet, competitive test. Test results with $q$-value $<0.05$ are in bold. Results with $q$-value between 0.05 and 0.1 are in italics. Full tables of $q$-values are presented in Supplementary Table 3. 
Table 4 Top 5 enriched ATC drug classes with gene-sets derived from the whole DSigDB (considering all drug classes)

\begin{tabular}{|c|c|c|c|c|c|}
\hline level3_codes & level3_name & pval self & qval self & $\begin{array}{c}\text { pval } \\
\text { compet }\end{array}$ & $\begin{array}{c}\text { qval } \\
\text { compet }\end{array}$ \\
\hline \multicolumn{6}{|c|}{ MDD-CONVERGE } \\
\hline D07A & CORTICOSTEROIDS, PLAIN & 3.83E-08 & 4.94E-06 & 1.77E-06 & $2.28 \mathrm{E}-04$ \\
\hline D07X & CORTICOSTEROIDS, OTHER COMBINATIONS & 5.04E-07 & 2.17E-05 & 7.56E-06 & $4.88 \mathrm{E}-04$ \\
\hline N06A & ANTIDEPRESSANTS & $3.35 \mathrm{E}-07$ & 2.16E-05 & 7.39E-05 & 2.57E-03 \\
\hline A07E & INTESTINAL ANTIINFLAMMATORY AGENTS & $2.16 \mathrm{E}-05$ & 4.64E-04 & $9.26 \mathrm{E}-05$ & $2.57 \mathrm{E}-03$ \\
\hline \multirow[t]{2}{*}{ S01C } & ANTIINFLAMMATORY AGENTS AND & $1.65 \mathrm{E}-05$ & $4.26 \mathrm{E}-04$ & $9.96 \mathrm{E}-05$ & 2.57E-03 \\
\hline & ANTIINFECTIVES IN COMBINATION & & & & \\
\hline \multicolumn{6}{|l|}{ MDD-PGC } \\
\hline \multirow[t]{2}{*}{ G01A } & ANTIINFECTIVES AND ANTISEPTICS, EXCL. & $2.50 \mathrm{E}-03$ & 3.23E-01 & 1.46E-04 & $1.88 \mathrm{E}-02$ \\
\hline & COMBINATIONS WITH CORTICOSTEROIDS & & & & \\
\hline \multirow[t]{2}{*}{ M01A } & ANTIINFLAMMATORY AND ANTIRHEUMATIC & 7.20E-03 & 4.64E-01 & 3.35E-04 & 2.16E-02 \\
\hline & PRODUCTS, NON-STEROIDS & & & & \\
\hline \multirow[t]{2}{*}{ L01C } & PLANT ALKALOIDS AND OTHER NATURAL & $1.92 \mathrm{E}-02$ & 8.26E-01 & 4.69E-03 & 2.02E-01 \\
\hline & PRODUCTS & & & & \\
\hline N05C & HYPNOTICS AND SEDATIVES & $1.73 \mathrm{E}-01$ & $1.00 \mathrm{E}+00$ & $1.08 \mathrm{E}-02$ & $3.48 \mathrm{E}-01$ \\
\hline L01X & OTHER ANTINEOPLASTIC AGENTS & 2.63E-01 & $1.00 \mathrm{E}+00$ & $1.35 \mathrm{E}-02$ & $3.48 \mathrm{E}-01$ \\
\hline \multicolumn{6}{|c|}{ Depressive symptoms } \\
\hline N01B & ANESTHETICS, LOCAL & 1.07E-07 & 1.19E-05 & $9.60 \mathrm{E}-06$ & $9.09 \mathrm{E}-04$ \\
\hline D08A & ANTISEPTICS AND DISINFECTANTS & $1.85 \mathrm{E}-07$ & 1.19E-05 & 1.41E-05 & $9.09 \mathrm{E}-04$ \\
\hline V03A & ALL OTHER THERAPEUTIC PRODUCTS & $3.27 \mathrm{E}-06$ & $1.41 \mathrm{E}-04$ & $1.74 \mathrm{E}-04$ & 7.48E-03 \\
\hline C10A & LIPID MODIFYING AGENTS, PLAIN & $6.81 \mathrm{E}-04$ & 1.94E-02 & 4.05E-03 & $1.31 \mathrm{E}-01$ \\
\hline N04B & DOPAMINERGIC AGENTS & $1.29 \mathrm{E}-03$ & $2.18 \mathrm{E}-02$ & $8.24 \mathrm{E}-03$ & 2.13E-01 \\
\hline \multicolumn{6}{|c|}{ Anxiety disorders } \\
\hline N06A & ANTIDEPRESSANTS & $6.05 \mathrm{E}-04$ & $6.97 \mathrm{E}-02$ & 2.14E-04 & $2.76 \mathrm{E}-02$ \\
\hline
\end{tabular}




\begin{tabular}{|c|c|c|c|c|c|}
\hline N05A & ANTIPSYCHOTICS & $1.71 \mathrm{E}-03$ & 7.35E-02 & 4.47E-04 & $2.88 \mathrm{E}-02$ \\
\hline L01B & ANTIMETABOLITES & $1.08 \mathrm{E}-03$ & 6.97E-02 & 7.03E-04 & $3.02 \mathrm{E}-02$ \\
\hline C07A & BETA BLOCKING AGENTS & 1.19E-02 & 3.17E-01 & $6.31 \mathrm{E}-03$ & 2.03E-01 \\
\hline N04A & ANTICHOLINERGIC AGENTS & 1.23E-02 & 3.17E-01 & $9.13 \mathrm{E}-03$ & 2.32E-01 \\
\hline \multicolumn{6}{|c|}{ Neuroticism } \\
\hline N05A & ANTIPSYCHOTICS & $1.21 \mathrm{E}-10$ & $1.56 \mathrm{E}-08$ & $1.52 \mathrm{E}-10$ & 1.96E-08 \\
\hline D01A & ANTIFUNGALS FOR TOPICAL USE & $2.98 \mathrm{E}-04$ & $1.92 \mathrm{E}-02$ & $3.31 \mathrm{E}-04$ & 2.13E-02 \\
\hline \multirow[t]{2}{*}{ G01A } & ANTIINFECTIVES AND ANTISEPTICS, EXCL. & 5.67E-04 & 2.44E-02 & $6.22 \mathrm{E}-04$ & 2.67E-02 \\
\hline & COMBINATIONS WITH CORTICOSTEROIDS & & & & \\
\hline N05C & HYPNOTICS AND SEDATIVES & $3.31 \mathrm{E}-03$ & 1.07E-01 & 4.03E-03 & $1.30 \mathrm{E}-01$ \\
\hline N06A & ANTIDEPRESSANTS & $6.15 \mathrm{E}-03$ & $1.58 \mathrm{E}-01$ & 7.84E-03 & $1.69 \mathrm{E}-01$ \\
\hline \multicolumn{6}{|c|}{ Simes $p$} \\
\hline N05A & ANTIPSYCHOTICS & 4.64E-07 & $3.82 \mathrm{E}-05$ & $9.11 \mathrm{E}-06$ & 7.35E-04 \\
\hline N06A & ANTIDEPRESSANTS & 5.93E-07 & $3.82 \mathrm{E}-05$ & $1.14 \mathrm{E}-05$ & 7.35E-04 \\
\hline \multirow[t]{2}{*}{ G01A } & ANTIINFECTIVES AND ANTISEPTICS, EXCL. & 4.53E-04 & $1.95 \mathrm{E}-02$ & $1.24 \mathrm{E}-03$ & $5.33 \mathrm{E}-02$ \\
\hline & COMBINATIONS WITH CORTICOSTEROIDS & & & & \\
\hline A01A & STOMATOLOGICAL PREPARATIONS & 7.37E-03 & $1.64 \mathrm{E}-01$ & $1.74 \mathrm{E}-02$ & 3.43E-01 \\
\hline V03A & ALL OTHER THERAPEUTIC PRODUCTS & 3.94E-03 & 1.27E-01 & 1.93E-02 & 3.43E-01 \\
\hline \multicolumn{6}{|c|}{ Brown's p } \\
\hline N05A & ANTIPSYCHOTICS & 2.31E-09 & 2.98E-07 & 8.77E-07 & 1.13E-04 \\
\hline N06A & ANTIDEPRESSANTS & $6.41 \mathrm{E}-09$ & 4.13E-07 & $3.58 \mathrm{E}-06$ & 2.31E-04 \\
\hline \multirow[t]{2}{*}{ G01A } & ANTIINFECTIVES AND ANTISEPTICS, EXCL. & 1.44E-04 & 4.64E-03 & $1.04 \mathrm{E}-03$ & 4.47E-02 \\
\hline & COMBINATIONS WITH CORTICOSTEROIDS & & & & \\
\hline V03A & ALL OTHER THERAPEUTIC PRODUCTS & 7.00E-05 & $3.01 \mathrm{E}-03$ & $2.86 \mathrm{E}-03$ & $9.22 \mathrm{E}-02$ \\
\hline NO4B & DOPAMINERGIC AGENTS & $1.61 \mathrm{E}-03$ & $3.46 \mathrm{E}-02$ & $9.57 \mathrm{E}-03$ & $2.24 \mathrm{E}-01$ \\
\hline
\end{tabular}

Self: self-contained test; Compet, competitive test. 
Table 5 Top 5 enriched ATC drug classes with gene-sets derived from PubChem and ChEMBL (considering all drug classes)

\begin{tabular}{|c|c|c|c|c|c|}
\hline $\begin{array}{l}\text { level3 } \\
\text { codes }\end{array}$ & level3_name & pval self & qval self & $\begin{array}{c}\text { pval } \\
\text { compet }\end{array}$ & $\begin{array}{c}\text { qval } \\
\text { compet }\end{array}$ \\
\hline \multicolumn{6}{|c|}{ MDD-PGC } \\
\hline N01A & ANESTHETICS, GENERAL & 4.06E-03 & 2.05E-01 & 2.94E-04 & 2.32E-02 \\
\hline N05C & HYPNOTICS AND SEDATIVES & 6.16E-02 & $1.00 \mathrm{E}+00$ & $7.86 \mathrm{E}-04$ & 2.77E-02 \\
\hline \multirow[t]{2}{*}{ L01C } & PLANT ALKALOIDS AND OTHER & $5.19 \mathrm{E}-03$ & 2.05E-01 & $1.05 \mathrm{E}-03$ & 2.77E-02 \\
\hline & NATURAL PRODUCTS & & & & \\
\hline N05B & ANXIOLYTICS & $6.25 \mathrm{E}-02$ & $1.00 \mathrm{E}+00$ & $1.68 \mathrm{E}-03$ & 3.00E-02 \\
\hline \multirow[t]{2}{*}{ L01X } & OTHER ANTINEOPLASTIC & $6.35 \mathrm{E}-01$ & $1.00 \mathrm{E}+00$ & $1.90 \mathrm{E}-03$ & 3.00E-02 \\
\hline & AGENTS & & & & \\
\hline \multicolumn{6}{|c|}{ MDD-CONVERGE } \\
\hline N05A & ANTIPSYCHOTICS & $5.54 \mathrm{E}-05$ & 4.38E-03 & 1.93E-04 & $1.52 \mathrm{E}-02$ \\
\hline \multirow[t]{2}{*}{ D08A } & ANTISEPTICS AND & 2.03E-03 & 7.90E-02 & $3.79 \mathrm{E}-03$ & $1.50 \mathrm{E}-01$ \\
\hline & DISINFECTANTS & & & & \\
\hline \multirow[t]{2}{*}{ A07E } & INTESTINAL & $3.00 \mathrm{E}-03$ & 7.90E-02 & 7.10E-03 & 1.87E-01 \\
\hline & ANTIINFLAMMATORY AGENTS & & & & \\
\hline \multirow[t]{2}{*}{ A03A } & DRUGS FOR FUNCTIONAL & $1.25 \mathrm{E}-02$ & $1.98 \mathrm{E}-01$ & $1.51 \mathrm{E}-02$ & $2.98 \mathrm{E}-01$ \\
\hline & GASTROINTESTINAL DISORDERS & & & & \\
\hline \multirow[t]{3}{*}{ G03X } & OTHER SEX HORMONES AND & 1.19E-02 & $1.98 \mathrm{E}-01$ & 1.99E-02 & 3.14E-01 \\
\hline & MODULATORS OF THE GENITAL & & & & \\
\hline & SYSTEM & & & & \\
\hline \multicolumn{6}{|c|}{ Anxiety case-control } \\
\hline N05A & ANTIPSYCHOTICS & 5.23E-07 & 4.13E-05 & 3.27E-08 & $2.58 \mathrm{E}-06$ \\
\hline N06A & ANTIDEPRESSANTS & $5.24 \mathrm{E}-04$ & 1.53E-02 & 1.17E-04 & $4.62 \mathrm{E}-03$ \\
\hline D01A & ANTIFUNGALS FOR TOPICAL USE & 5.81E-04 & 1.53E-02 & 2.42E-04 & 6.37E-03 \\
\hline
\end{tabular}




$\begin{array}{llllll}\text { J02A } & \text { ANTIMYCOTICS FOR SYSTEMIC } & 3.39 \mathrm{E}-03 & 6.70 \mathrm{E}-02 & 2.52 \mathrm{E}-03 & 4.25 \mathrm{E}-02 \\ & \text { USE } & & & & \\ \text { N02C } & \text { ANTIMIGRAINE PREPARATIONS } & 6.06 \mathrm{E}-03 & 9.57 \mathrm{E}-02 & 2.69 \mathrm{E}-03 & 4.25 \mathrm{E}-02 \\ \begin{array}{l}\text { Depressive symptoms } \\ \text { N04B }\end{array} & \text { DOPAMINERGIC AGENTS } & 1.03 \mathrm{E}-04 & 4.05 \mathrm{E}-03 & 1.46 \mathrm{E}-03 & 7.79 \mathrm{E}-02 \\ \text { N03A } & \text { ANTIEPILEPTICS } & 1.01 \mathrm{E}-04 & 4.05 \mathrm{E}-03 & 2.62 \mathrm{E}-03 & 7.79 \mathrm{E}-02 \\ \text { L01B } & \text { ANTIMETABOLITES } & 3.34 \mathrm{E}-04 & 5.36 \mathrm{E}-03 & 2.96 \mathrm{E}-03 & 7.79 \mathrm{E}-02 \\ \text { M03A } & \text { MUSCLE RELAXANTS, } & 2.87 \mathrm{E}-03 & 2.22 \mathrm{E}-02 & 4.82 \mathrm{E}-03 & 9.22 \mathrm{E}-02 \\ & \text { PERIPHERALLY ACTING AGENTS } & & & & \\ \text { L01A } & \text { ALKYLATING AGENTS } & 2.08 \mathrm{E}-03 & 2.05 \mathrm{E}-02 & 5.83 \mathrm{E}-03 & 9.22 \mathrm{E}-02 \\ \text { Neuroticism } & & & & & \\ \text { N05A } & \text { ANTIPSYCHOTICS } & 2.64 \mathrm{E}-13 & 2.09 \mathrm{E}-11 & 4.31 \mathrm{E}-10 & 3.40 \mathrm{E}-08 \\ \text { N05B } & \text { ANXIOLYTICS } & 9.25 \mathrm{E}-04 & 3.65 \mathrm{E}-02 & 6.92 \mathrm{E}-03 & 2.73 \mathrm{E}-01 \\ \text { N05C } & \text { HYPNOTICS AND SEDATIVES } & 1.70 \mathrm{E}-03 & 4.48 \mathrm{E}-02 & 1.39 \mathrm{E}-02 & 3.66 \mathrm{E}-01 \\ \text { N04B } & \text { DOPAMINERGIC AGENTS } & 7.60 \mathrm{E}-03 & 1.00 \mathrm{E}-01 & 2.99 \mathrm{E}-02 & 5.78 \mathrm{E}-01 \\ \text { R06A } & \text { ANTIHISTAMINES FOR SYSTEMIC } & 3.38 \mathrm{E}-03 & 5.40 \mathrm{E}-02 & 3.66 \mathrm{E}-02 & 5.78 \mathrm{E}-01 \\ & \text { USE } & & & & \\ \text { Simes } \mathbf{p} & & & & & \\ \text { N05A } & \text { ANTIPSYCHOTICS } & & & & \\ \text { N04B } & \text { DOPAMINERGIC AGENTS } & 1.90 \mathrm{E}-04 & 7.51 \mathrm{E}-03 & 5.58 \mathrm{E}-04 & 2.20 \mathrm{E}-02 \\ \text { L01A } & \text { ALKYLATING AGENTS } & 1.90 \mathrm{E}-03 & 4.86 \mathrm{E}-02 & 3.19 \mathrm{E}-03 & 8.40 \mathrm{E}-02 \\ \text { L02B } & \text { HORMONE ANTAGONISTS AND } & 3.32 \mathrm{E}-03 & 5.25 \mathrm{E}-02 & 5.36 \mathrm{E}-03 & 1.06 \mathrm{E}-01 \\ & \text { RELATED AGENTS } & & & & \\ \text { N02C } & \text { ANTIMIGRAINE PREPARATIONS } & 2.46 \mathrm{E}-03 & 4.86 \mathrm{E}-02 & 7.81 \mathrm{E}-03 & 1.23 \mathrm{E}-01\end{array}$

\section{Brown $\mathrm{p}$}

N05A ANTIPSYCHOTICS

7.68E-11 6.07E-09 6.57E-09 5.19E-07 


\begin{tabular}{llllll} 
N04B & DOPAMINERGIC AGENTS & $7.68 \mathrm{E}-05$ & $3.03 \mathrm{E}-03$ & $2.87 \mathrm{E}-04$ & $1.13 \mathrm{E}-02$ \\
L02B & HORMONE ANTAGONISTS AND & $3.14 \mathrm{E}-03$ & $4.96 \mathrm{E}-02$ & $5.99 \mathrm{E}-03$ & $1.44 \mathrm{E}-01$ \\
& RELATED AGENTS & & & & \\
N02C & ANTIMIGRAINE PREPARATIONS & $1.64 \mathrm{E}-03$ & $3.24 \mathrm{E}-02$ & $7.30 \mathrm{E}-03$ & $1.44 \mathrm{E}-01$ \\
N06A & ANTIDEPRESSANTS & $1.08 \mathrm{E}-03$ & $2.84 \mathrm{E}-02$ & $1.68 \mathrm{E}-02$ & $2.65 \mathrm{E}-01$ \\
\hline
\end{tabular}

Self: self-contained test; Compet, competitive test. 
Table 6 Selected repositioning hits with literature support

\begin{tabular}{|c|c|c|c|c|}
\hline Drug & Phenotype & pval & qval & Drug Description \\
\hline Oxotremorine-M & MDD-converge & $2.54 \mathrm{E}-03$ & 9.19E-01 & Muscarinic agonist; ameliorated depression-like symptoms in rats \\
\hline Capeserod & MDD-converge & $6.66 \mathrm{E}-03$ & 9.19E-01 & 5-HT4 partial agonist; ADP-like effects in rats \\
\hline Entacapone & MDD-converge & $3.28 \mathrm{E}-05$ & $3.43 \mathrm{E}-02$ & Reversible COMT inhibitor; ADP effects of COMT inhibitor in an open clinical study \\
\hline DHEA sulfate & MDD-converge & 2.44E-04 & 8.49E-02 & Neurosteroid and neurotrophin; open clinical study showed effects in MDD \\
\hline $\begin{array}{l}\text { naringenin } \\
\text { chalcone }\end{array}$ & MDD-converge & 4.99E-04 & $1.45 \mathrm{E}-01$ & Citrus bioflavonoid; BDNF-dependent ADP effects in mice \\
\hline amoxapine & MDD-converge & $8.69 \mathrm{E}-04$ & 2.27E-01 & Tetracyclic antidepressant \\
\hline Ibuprofen & MDD-PGC & 2.41E-03 & $9.71 \mathrm{E}-01$ & Associated lower depression score in patients with osteoarthritis \\
\hline Cytomel & MDD-PGC & $1.70 \mathrm{E}-02$ & $1.00 \mathrm{E}+00$ & Synthetic T3; known augmentation therapy for MDD \\
\hline $\begin{array}{l}\text { Guanidinyl-naltrin } \\
\text { dole } \\
\text { di-trifluoroacetate }\end{array}$ & MDD-PGC & 2.32E-02 & $1.00 \mathrm{E}+00$ & Transient $\kappa$-opioid receptor inhibitors showed antidepressant(ADP)-like efficacy in rats \\
\hline Piperlongumine & $\begin{array}{l}\text { MDD-PGC, } \\
\text { Dep Sym }\end{array}$ & 2.52E-04 & $2.81 \mathrm{E}-01$ & $\begin{array}{l}\text { A constituent of Piper longum fruit; shown to confer resistance against stress in a mouse } \\
\text { model }\end{array}$ \\
\hline Sanguinarine & MDD-PGC & $9.63 \mathrm{E}-04$ & 4.60E-01 & $\begin{array}{l}\text { Selective mitogen-activated protein kinase phosphatase-1 (Mkp-1) inhibitor; shown to } \\
\text { produce antidepressant-like effect in rats }\end{array}$ \\
\hline Prochlorperazine & $\begin{array}{l}\text { DepSym, } \\
\text { anxiety CC }\end{array}$ & $8.68 \mathrm{E}-04$ & $2.80 \mathrm{E}-01$ & Antipsychotic \\
\hline Oleamide & DepSym & $1.98 \mathrm{E}-03$ & 4.56E-01 & Act on cannabinoid signaling; anxiolytic and ADP-like effects in mice \\
\hline ellagic acid & DepSym & $9.58 \mathrm{E}-03$ & $5.61 \mathrm{E}-01$ & Antioxidant; Anxiolytic and ADP-like effects in mice, may involve GABAergic actions \\
\hline LY-367,265 & DepSym & 1.05E-02 & $5.61 \mathrm{E}-01$ & 5-HT2A receptor antagonist, SSRI \\
\hline protriptyline & DepSym & $1.11 \mathrm{E}-02$ & $5.61 \mathrm{E}-01$ & Tricyclic antidepressant (TCA) \\
\hline Alsterpaullone & DepSym & 2.53E-07 & 4.41E-04 & $\begin{array}{l}\text { Competitive inhibitor of GSK-3 } 3 \text {; GSK3 inhibition is implicated in various psychiatric } \\
\text { disorders, including depression }\end{array}$ \\
\hline $\mathrm{H}-7$ & DepSym & $3.43 \mathrm{E}-05$ & $1.12 \mathrm{E}-02$ & Selective NMDA receptor (NMDAR) antagonist \\
\hline
\end{tabular}




\begin{tabular}{|c|c|c|c|c|}
\hline Trazodone & Anxiety CC & $1.28 \mathrm{E}-04$ & $2.06 \mathrm{E}-01$ & Serotonin antagonist and reuptake inhibitor; known ADP \\
\hline ritanserin & Anxiety CC & 7.01E-04 & $5.64 \mathrm{E}-01$ & $\begin{array}{l}\text { Selective 5-HT2A and 5-HT2C antagonist; ADP and anxiolytic effects shown in clinical } \\
\text { trials }\end{array}$ \\
\hline Pregabalin & Anxiety CC & $9.47 \mathrm{E}-03$ & $9.89 \mathrm{E}-01$ & Known treatment for generalized anxiety disorder \\
\hline gabapentin & Anxiety CC & $1.29 \mathrm{E}-02$ & $9.89 \mathrm{E}-01$ & Similar mechanism to pregabalin; act on GABAergic transmission \\
\hline $\begin{array}{l}\text { Clomipramine } \\
\text { hydrochloride }\end{array}$ & Anxiety CC & $1.76 \mathrm{E}-02$ & $9.89 \mathrm{E}-01$ & Tricyclic antidepressant (TCA) \\
\hline pindolol & Anxiety CC & $1.90 \mathrm{E}-02$ & $9.89 \mathrm{E}-01$ & $\begin{array}{l}\text { Beta blocker with partial agonist activity; clinical trials showed efficacy as augmentation } \\
\text { therapy in depression }\end{array}$ \\
\hline quipazine & Anxiety CC & $9.90 \mathrm{E}-04$ & $6.12 \mathrm{E}-01$ & Piperazine-based nonselective 5-HT receptor agonist \\
\hline fendiline & $\begin{array}{l}\text { Neuroticism, } \\
\text { MDD-PGC }\end{array}$ & 3.03E-11 & $1.58 \mathrm{E}-07$ & $\begin{array}{l}\text { Nonselective calcium channel blocker; produce ADP-like effects in mouse models by } \\
\text { inhibition of acid sphingomyelinase and reduction of ceramide levels }\end{array}$ \\
\hline
\end{tabular}

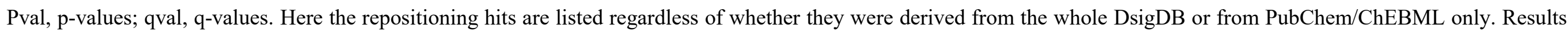
from meta-analysis (Simes' or Brown's method) are not specifically listed as they are included in the results of individual phenotypes.

Please also refer to the legends of Table 1 and the main text for the references and more detailed discussions. 
1. World Health Organization. Depression and Other Common Mental Disorders Global Health Estimates. Available at http://apps.who.int/iris/bitstream/10665/254610/1/WHO-MSD-MER-2017.2-eng.pdf?ua=1. (2017).

2. Frances, A. et al. Relationship of Anxiety and Depression. Psychopharmacology 106, S82-S86 (1992).

3. Goodwin, G.M. The overlap between anxiety, depression, and obsessive-compulsive disorder. Dialogues in Clinical Neuroscience 17, 249-260 (2015).

4. Trivedi, M.H. et al. Evaluation of outcomes with citalopram for depression using measurement-based care in STAR*D: Implications for clinical practice. American Journal of Psychiatry 163, 28-40 (2006).

5. Al-Harbi, K.S. Treatment-resistant depression: therapeutic trends, challenges, and future directions. Patient Preference and Adherence 6, 369-388 (2012).

6. Papassotiropoulos, A. \& de Quervain, D.J.F. Failed drug discovery in psychiatry: time for human genome-guided solutions. Trends in Cognitive Sciences 19, 183-187 (2015).

7. Sanseau, P. et al. Use of genome-wide association studies for drug repositioning. Nat Biotechnol 30, 317-20 (2012).

8. Anighoro, A., Bajorath, J. \& Rastelli, G. Polypharmacology: Challenges and Opportunities in Drug Discovery. Journal of Medicinal Chemistry 57, 7874-7887 (2014).

9. Maciejewski, H. Gene set analysis methods: statistical models and methodological differences. Briefings in Bioinformatics 15, 504-518 (2014).

10. de Leeuw, C.A., Neale, B.M., Heskes, T. \& Posthuma, D. The statistical properties of gene-set analysis. Nature Reviews Genetics 17, 353-364 (2016).

11. de Jong, S., Vidler, L.R., Mokrab, Y., Collier, D.A. \& Breen, G. Gene-set analysis based on the pharmacological profiles of drugs to identify repurposing opportunities in schizophrenia. $J$ Psychopharmacol 30, 826-30 (2016).

12. Gaspar, H.A. \& Breen, G. Pathways analyses of schizophrenia GWAS focusing on known and novel drug targets. bioRxiv, 091264 (2016).

13. Ruderfer, D.M. et al. Polygenic overlap between schizophrenia risk and antipsychotic response: a genomic medicine approach. Lancet Psychiatry 3, 350-357 (2016).

14. Sullivan, P.F. et al. A mega-analysis of genome-wide association studies for major depressive disorder. Molecular Psychiatry 18, 497-511 (2013).

15. Cai, N. et al. Sparse whole-genome sequencing identifies two loci for major depressive disorder. Nature 523, 588-+ (2015).

16. Okbay, A. et al. Genetic variants associated with subjective well-being, depressive symptoms, and neuroticism identified through genome-wide analyses (vol 48, pg 624, 2016). Nature Genetics 48, 1591-1591 (2016).

17. Lahey, B.B. Public Health Significance of Neuroticism. American Psychologist 64, 241-256 (2009).

18. Tang, T.Z. et al. Personality Change During Depression Treatment A Placebo-Controlled Trial. Archives of General Psychiatry 66, 1322-1330 (2009).

19. Otowa, T. et al. Meta-analysis of genome-wide association studies of anxiety disorders. Molecular Psychiatry 21, 1391-1399 (2016).

20. Yoo, M. et al. DSigDB: drug signatures database for gene set analysis. Bioinformatics 31, 3069-3071 (2015).

21. Kim, S. et al. PubChem Substance and Compound databases. Nucleic Acids Research 44, D1202-D1213 (2016).

22. Gaulton, A. et al. ChEMBL: a large-scale bioactivity database for drug discovery. Nucleic Acids Research 40, D1100-D1107 (2012). 
23. Lamb, J. et al. The connectivity map: Using gene-expression signatures to connect small molecules, genes, and disease. Science 313, 1929-1935 (2006).

24. Mattingly, C.J., Colby, G.T., Forrest, J.N. \& Boyer, J.L. The Comparative Toxicogenomics Database (CTD). Environmental Health Perspectives 111, $793-795$ (2003).

25. Bakshi, A. et al. Fast set-based association analysis using summary data from GWAS identifies novel gene loci for human complex traits. Scientific Reports 6(2016).

26. Liu, J.Z. et al. A Versatile Gene-Based Test for Genome-wide Association Studies. American Journal of Human Genetics 87, 139-145 (2010).

27. Purcell, S. et al. PLINK: A tool set for whole-genome association and population-based linkage analyses. American Journal of Human Genetics 81, 559-575 (2007).

28. de Leeuw, C.A., Mooij, J.M., Heskes, T. \& Posthuma, D. MAGMA: Generalized Gene-Set Analysis of GWAS Data. Plos Computational Biology 11(2015).

29. Simes, R.J. An improved Bonferroni procedure for multiple tests of significance. Biometrika, 751-754 (1986).

30. Brown, M.B. 400: A method for combining non-independent, one-sided tests of significance. Biometrics, 987-992 (1975).

31. Poole, W., Gibbs, D.L., Shmulevich, I., Bernard, B. \& Knijnenburg, T.A. Combining dependent P-values with an empirical adaptation of Brown's method. Bioinformatics 32, 430-436 (2016).

32. Sarkar, S.K. \& Chang, C.-K. The Simes method for multiple hypothesis testing with positively dependent test statistics. Journal of the American Statistical Association 92, 1601-1608 (1997).

33. Wei, W.Q. et al. Development and evaluation of an ensemble resource linking medications to their indications. $J$ Am Med Inform Assoc 20, 954-61 (2013).

34. Benjamini, Y. \& Hochberg, Y. Controlling the False Discovery Rate - a Practical and Powerful Approach to Multiple Testing. Journal of the Royal Statistical Society Series B-Methodological 57, 289-300 (1995).

35. Kanba, S. Although antidepressants and anxiolytics are frequently used together to treat depression in the acute phase, how effective is the concomitant use of these drugs? Journal of Psychiatry and Neuroscience 29, 485-486 (2004).

36. Steenen, S.A. et al. Propranolol for the treatment of anxiety disorders: Systematic review and meta-analysis. $J$ Psychopharmacol 30, 128-39 (2016).

37. Gulbins, E. et al. Acid sphingomyelinase-ceramide system mediates effects of antidepressant drugs. Nature Medicine 19, 934-+ (2013).

38. Yi, L.T. et al. BDNF signaling is necessary for the antidepressant-like effect of naringenin. Progress in Neuro-Psychopharmacology \& Biological Psychiatry 48, 135-141 (2014).

39. Jue, S.G., Dawson, G.W. \& Brogden, R.N. Amoxapine - a Review of Its Pharmacology and Efficacy in Depressed States. Drugs 24, 1-23 (1982).

40. Yadav, V., Chatterjee, S.S., Majeed, M. \& Kumar, V. Long lasting preventive effects of piperlongumine and a Piper longum extract against stress triggered pathologies in mice. Journal of Intercultural Ethnopharmacology 4 , 277-283 (2015).

41. Chen, Y.C. et al. Microinjection of sanguinarine into the ventrolateral orbital cortex inhibits Mkp-1 and exerts an antidepressant-like effect in rats. Neuroscience Letters 506, 327-331 (2012).

42. Fuller, R.W. et al. The effects of quipazine on serotonin metabolism in rat brain. Life Sci 18, 925-33 (1976). 
43. Leost, M. et al. Paullones are potent inhibitors of glycogen synthase kinase-3 beta and cyclin-dependent kinase 5/p25. European Journal of Biochemistry 267, 5983-5994 (2000).

44. Beaulieu, J.M. et al. Role of GSK3 beta in behavioral abnormalities induced by serotonin deficiency. Proceedings of the National Academy of Sciences of the United States of America 105, 1333-1338 (2008).

45. Freland, L. \& Beaulieu, J.M. Inhibition of GSK3 by lithium, from single molecules to signaling networks. Frontiers in Molecular Neuroscience 5(2012).

46. Amador, M. \& Dani, J.A. Protein kinase inhibitor, H-7, directly affects N-methyl-D-aspartate receptor channels. Neurosci Lett 124, 251-5 (1991).

47. Fung, M. Evaluation of the characteristics of safety withdrawal of prescription drugs from worldwide pharmaceutical markets-1960 to 1999. Drug Information Journal 35, 293-317 (2001).

48. Cipriani, A. et al. A systematic review of calcium channel antagonists in bipolar disorder and some considerations for their future development. Molecular Psychiatry 21, 1324-1332 (2016).

49. Ostacher, M.J. et al. Pilot investigation of isradipine in the treatment of bipolar depression motivated by genome-wide association. Bipolar Disorders 16, 199-203 (2014).

50. Dubovsky, S.L., Buzan, R., Thomas, M., Kassner, C. \& Cullum, C.M. Nicardipine improves the antidepressant action of ECT but does not improve cognition. $J$ ECT 17, 3-10 (2001).

51. Veena, J., Srikumar, B.N., Mahati, K., Raju, T.R. \& Shankaranarayana Rao, B.S. Oxotremorine treatment restores hippocampal neurogenesis and ameliorates depression-like behaviour in chronically stressed rats. Psychopharmacology (Berl) 217, 239-53 (2011).

52. Tamburella, A., Micale, V., Navarria, A. \& Drago, F. Antidepressant properties of the 5-HT4 receptor partial agonist, SL65.0155: behavioral and neurochemical studies in rats. Prog Neuropsychopharmacol Biol Psychiatry 33, 1205-10 (2009).

53. Iyengar, R.L. et al. NSAIDs are associated with lower depression scores in patients with osteoarthritis. Am J Med 126, 1017 e11-8 (2013).

54. Zaminelli, T. et al. Antidepressant and Antioxidative Effect of Ibuprofen in the Rotenone Model of Parkinson's Disease. Neurotoxicity Research 26, 351-362 (2014).

55. Touma, K.T.B., Zoucha, A.M. \& Scarff, J.R. Liothyronine for Depression: A Review and Guidance for Safety Monitoring. Innov Clin Neurosci 14, 24-29 (2017).

56. Peters, M.F. et al. Identification of short-acting kappa-opioid receptor antagonists with anxiolytic-like activity. European Journal of Pharmacology 661, 27-34 (2011).

57. Pande, A.C. et al. Pregabalin in generalized anxiety disorder: A placebo-controlled trial. American Journal of Psychiatry 160, 533-540 (2003).

58. Rickels, K. et al. Pregabalin for treatment of generalized anxiety disorder - A 4-week, multicenter, double-blind, placebo-controlled trial of pregabalin and alprazolam. Archives of General Psychiatry 62, 1022-1030 (2005).

59. Nappi, G. et al. A New 5-Ht2 Antagonist (Ritanserin) in the Treatment of Chronic Headache with Depression - a Double-Blind-Study Vs Amitriptyline. Headache 30, 439-444 (1990).

60. Ceulemans, D.L., Hoppenbrouwers, M.L., Gelders, Y.G. \& Reyntjens, A.J. The influence of ritanserin, a serotonin antagonist, in anxiety disorders: a double-blind placebo-controlled study versus lorazepam. Pharmacopsychiatry 18, 303-5 (1985).

61. Strauss, W.H. \& Klieser, E. Psychotropic effects of ritanserin, a selective S2 antagonist: an open study. Eur Neuropsychopharmacol 1, 101-5 (1991). 
62. Blier, P. \& Bergeron, R. Effectiveness of pindolol with selected antidepressant drugs in the treatment of major depression. J Clin Psychopharmacol 15, 217-22 (1995).

63. Artigas, F., Celada, P., Laruelle, M. \& Adell, A. How does pindolol improve antidepressant action? Trends in Pharmacological Sciences 22, 224-228 (2001).

64. Wei, X.Y., Yang, J.Y., Dong, Y.X. \& Wu, C.F. Anxiolytic-like effects of oleamide in group-housed and socially isolated mice. Progress in Neuro-Psychopharmacology \& Biological Psychiatry 31, 1189-1195 (2007).

65. Fedorova, I. et al. Behavioral evidence for the interaction of oleamide with multiple neurotransmitter systems. $J$ Pharmacol Exp Ther 299, 332-42 (2001).

66. Dhingra, D. \& Chhillar, R. Antidepressant-like activity of ellagic acid in unstressed and acute immobilization-induced stressed mice. Pharmacol Rep 64, 796-807 (2012).

67. Girish, C., Raj, V., Arya, J. \& Balakrishnan, S. Involvement of the GABAergic system in the anxiolytic-like effect of the flavonoid ellagic acid in mice. Eur J Pharmacol 710, 49-58 (2013).

68. Onasanwo, S. et al. Antidepressant and Anxiolytic Potentials of Chebulinic Acid in Laboratory Rodent. Ann Depress Anxiety 1, 1032 (2014).

69. Philip, N.S., Carpenter, L.L., Tyrka, A.R. \& Price, L.H. The Nicotinic Acetylcholine Receptor as a Target for Antidepressant Drug Development. Scientific World Journal (2012).

70. Goldberg, D. The heterogeneity of "major depression". World Psychiatry 10, 226-8 (2011).

71. Fournier, J.C. et al. Antidepressant drug effects and depression severity: a patient-level meta-analysis. JAMA 303, 47-53 (2010).

72. Kirsch, I. et al. Initial severity and antidepressant benefits: a meta-analysis of data submitted to the Food and Drug Administration. PLoS Med 5, e45 (2008).

73. Spielmans, G.I. et al. Adjunctive atypical antipsychotic treatment for major depressive disorder: a meta-analysis of depression, quality of life, and safety outcomes. PLoS Med 10, e1001403 (2013).

74. Zhou, X.Y. et al. Atypical Antipsychotic Augmentation for Treatment-Resistant Depression: A Systematic Review and Network Meta-Analysis. International Journal of Neuropsychopharmacology 18(2015).

75. Gao, K., Muzina, D., Gajwani, P. \& Calabrese, J.R. Efficacy of typical and atypical antipsychotics for primary and comorbid anxiety symptoms or disorders: a review. J Clin Psychiatry 67, 1327-40 (2006).

76. Samuel, M., Zimovetz, E.A., Gabriel, Z. \& Beard, S.M. Efficacy and safety of treatments for refractory generalized anxiety disorder: a systematic review. Int Clin Psychopharmacol 26, 63-8 (2011).

77. LaLonde, C.D. \& Van Lieshout, R.J. Treating generalized anxiety disorder with second generation antipsychotics: a systematic review and meta-analysis. J Clin Psychopharmacol 31, 326-33 (2011).

78. Cross-Disorder Group of the Psychiatric Genomics, C. et al. Genetic relationship between five psychiatric disorders estimated from genome-wide SNPs. Nat Genet 45, 984-94 (2013).

79. Smith, D.J. et al. Genome-wide analysis of over 106000 individuals identifies 9 neuroticism-associated loci. Molecular Psychiatry 21, 749-757 (2016).

80. Malouff, J.M., Thorsteinsson, E.B. \& Schutte, N.S. The relationship between the five-factor model of personality and symptoms of clinical disorders: A meta-analysis. Journal of Psychopathology and Behavioral Assessment 27, 101-114 (2005).

81. Miller, A.H. \& Raison, C.L. The role of inflammation in depression: from evolutionary imperative to modern treatment target. Nature Reviews Immunology 16, 22-34 (2016). 
82. Kohler, O., Petersen, L., Mors, O. \& Gasse, C. Inflammation and depression: combined use of selective serotonin reuptake inhibitors and NSAIDs or paracetamol and psychiatric outcomes. Brain and Behavior 5(2015).

83. Kohler, O. et al. Effect of Anti-inflammatory Treatment on Depression, Depressive Symptoms, and Adverse Effects A Systematic Review and Meta-analysis of Randomized Clinical Trials. Jama Psychiatry 71, 1381-1391 (2014).

84. Gold, P.W. \& Chrousos, G.P. Organization of the stress system and its dysregulation in melancholic and atypical depression: high vs low CRH/NE states. Molecular Psychiatry 7, 254-275 (2002).

85. Stetler, C. \& Miller, G.E. Depression and Hypothalamic-Pituitary-Adrenal Activation: A Quantitative Summary of Four Decades of Research. Psychosomatic Medicine 73, 114-126 (2011).

86. Lamers, F. et al. Evidence for a differential role of HPA-axis function, inflammation and metabolic syndrome in melancholic versus atypical depression. Molecular Psychiatry 18, 692-699 (2013).

87. Pariante, C.M. The glucocorticoid receptor: part of the solution or part of the problem? J Psychopharmacol 20, 79-84 (2006).

88. Kling, M.A., Coleman, V.H. \& Schulkin, J. Glucocorticoid Inhibition in the Treatment of Depression: Can We Think Outside the Endocrine Hypothalamus? Depression and Anxiety 26, 641-649 (2009).

89. Goodwin, G.M. et al. The Effects of Cortisol Infusion Upon Hormone-Secretion from the Anterior-Pituitary and Subjective Mood in Depressive-Illness and in Controls. Journal of Affective Disorders 26, 73-84 (1992).

90. Arana, G.W. et al. Dexamethasone for the Treatment of Depression - a Randomized, Placebo-Controlled, Double-Blind Trial. American Journal of Psychiatry 152, 265-267 (1995).

91. Dinan, T.G. et al. Dexamethasone augmentation in treatment-resistant depression. Acta Psychiatrica Scandinavica 95, 58-61 (1997).

92. DeBattista, C., Posener, J.A., Kalehzan, B.M. \& Schatzberg, A.F. Acute antidepressant effects of intravenous hydrocortisone and $\mathrm{CRH}$ in depressed patients: A double-blind, placebo-controlled study. American Journal of Psychiatry 157, 1334-1337 (2000).

93. Nierenberg, A.A., Dougherty, D. \& Rosenbaum, J.F. Dopaminergic agents and stimulants as antidepressant augmentation strategies. Journal of Clinical Psychiatry 59, 60-64 (1998).

94. Dell'Osso, B., Ketter, T.A., Cremaschi, L., Spagnolin, G. \& Altamura, A.C. Assessing the Roles of Stimulants/Stimulant-like Drugs and Dopamine-agonists in the Treatment of Bipolar Depression. Current Psychiatry Reports 15(2013).

95. Corp, S.A., Gitlin, M.J. \& Altshuler, L.L. A Review of the Use of Stimulants and Stimulant Alternatives in Treating Bipolar Depression and Major Depressive Disorder. Journal of Clinical Psychiatry 75, 1010-1018 (2014).

96. Szmulewicz, A.G. et al. Dopaminergic agents in the treatment of bipolar depression: a systematic review and meta-analysis. Acta Psychiatrica Scandinavica 135, 527-538 (2017).

97. Antonaci, F. et al. Migraine and psychiatric comorbidity: a review of clinical findings. Journal of Headache and Pain 12, 115-125 (2011).

98. Koch, H.J. \& Jurgens, T.P. Antidepressants in Long-Term Migraine Prevention. Drugs 69, 1-19 (2009).

99. Salagre, E., Fernandes, B.S., Dodd, S., Brownstein, D.J. \& Berk, M. Statins for the treatment of depression: A meta-analysis of randomized, double-blind, placebo-controlled trials. Journal of Affective Disorders 200, 235-242 (2016).

100. Kohler, O. et al. The Effect of Concomitant Treatment With SSRIs and Statins: A Population-Based Study. American Journal of Psychiatry 173, 807-815 (2016). 
bioRxiv preprint doi: https://doi.org/10.1101/132563; this version posted September 8, 2017. The copyright holder for this preprint (which

was not certified by peer review) is the author/funder, who has granted bioRxiv a license to display the preprint in perpetuity. It is made available under aCC-BY-NC-ND 4.0 International license.

101. You, H., Lu, W., Zhao, S.P., Hu, Z.P. \& Zhang, J.N. The relationship between statins and depression: a review of the literature. Expert Opinion on Pharmacotherapy 14, 1467-1476 (2013).

102. So, H.C. et al. Analysis of genome-wide association data highlights candidates for drug repositioning in psychiatry. Nat Neurosci (2017). 